\title{
INTERACTIVE RETENTION INDEX DATABASE FOR COMPOUND IDENTIFICATION IN TEMPERATURE-PROGRAMMED CAPILLARY GAS CHROMATOGRAPHY
}

\author{
Y. GUAN, J. KIRALY and J. A. RIJKS* \\ Department of Chemical Technology, Laboratory of Instrumental Analysis, Eindhoven University of \\ Technology, P.O. Box 513,5600 MB Eindhoven (The Netherlands)
}

(First received November 16th, 1988; revised manuscript received February 13th, 1989)

\section{SUMMARY}

A procedure is described and evaluated that allows the calculation of linear temperature-programmed retention indices from accurate Kováts retention indices on a given stationary phase and their temperature variation coefficients. The influence of experimental factors such as column film thickness, phase ratio and variation of Kováts retention indices, column dead time and carrier gas flow-rates are examined. The calculation accuracies are $\leq 0.5$ retention index units in most instances. The applicability and limitations of the procedure are discussed.

\section{INTRODUCTION}

Large numbers of isothermal gas chromatographic retention data have been published as Kováts retention indices. The use of Kováts retention indices has a great advantage over relative retention times, retention volumes or capacity ratios in that they are independent of the film thickness, column dimensions and phase ratio. Owing to the advances in column technology, highly reproducible (expressed as Kováts' indices) columns are commercially available for non-polar and some polar stationary phases.

The prediction or calculation of linear temperature-programmed retention indices (LTPRI) from isothermal data has been explored in the past ${ }^{1-6}$ and different approaches were proposed and evaluated. Owing to the difference between the LTPRI and Kováts systems in the definition of retention index, the correct way to convert isothermal retention data to LTPRI is through the thermodynamic parameters of components as established by Curvers et al. ${ }^{1}$. It is feasible in theory to transfer the isothermal data (capacity ratios or Kováts retention indices) in terms of entropy and enthalpy of each component from one column to another for columns with the same stationary phase but different dimensions. However, in practice, this is not as easy as it may seem. The entropy term $[\exp (\Delta S / R) / \beta]$ is dependent on the phase ratio $(\beta)$ and is difficult to determine accurately owing to the uncertainty in the measurement of the phase ratio. It has been observed experimentally that the enthalpy terms are also 
dependent on the phase ratio ${ }^{1}$. Some of them are unexpectedly large, whereas theoretically they should remain constant.

The objectives of the study reported here were (a) direct utilization of Kovats retention indices, either measured or published, for calculating LTPRI; and (b) to find a means of eliminating the necessity to determine the film thickness or phase ratio and the corresponding changes in entropy and enthalpy.

\section{THEORY}

\section{Calculation}

For a given component $i$ at a given temperature $T$, the Kováts retention index is

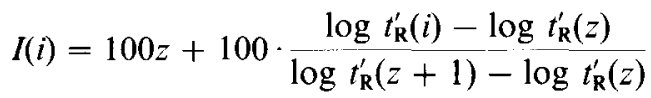

Substitution of $t_{\mathbf{R}}^{\prime}(i) / t_{\mathbf{R}}^{\prime}(j)=k(i) / k(j)$ in eqn. 1 and rearranging yields

$$
\log k(i)=\frac{I(i)-100 z}{100} \cdot \log \left[\frac{k(z+1)}{k(z)}\right]+\log k(z)
$$

Converting both sides of the equation into natural logarithm gives

$$
\ln k(i)=\frac{I(i)-100 z}{100} \cdot \ln \left[\frac{k(z+1)}{k(z)}\right]+\ln k(z)
$$

One should bear in mind that all variables in eqns. 1-3 are temperature dependent. To make it explicit, $k(i, T)$ is used instead of $k(i)$ in the following equations.

Using the well known equation

$$
\ln k(i, T)=\ln \left[\frac{\alpha(i)}{\beta}\right]-\frac{\Delta H(i)}{R T}
$$

where $\alpha=\exp [\Delta S(i) / R]$, together with eqn. 3, we obtain the desired equations:

$$
-\frac{\Delta H(i)}{R}=\left[\ln k\left(i, T_{1}\right)-\ln k\left(i, T_{2}\right)\right]\left(\frac{T_{1} T_{2}}{T_{2}-T_{1}}\right)
$$

and

$$
\frac{\alpha(i)}{\beta}=\exp \left[\ln k(i, T)-\frac{\Delta H(i)}{R T}\right]
$$

where $T$ can be $T_{1}$ or $T_{2}$.

Apart from the Kováts retention index of components at two temperatures, the only additional information needed for the calculation of the entropy and enthalpy terms is the adjusted retention time (or capacity ratio) of $n$-alkanes measured at two 
corresponding temperatures on the column used for analysis. Subsequent calculations of the temperature-programmed retention temperature or retention time of each component use the well defined relationship ${ }^{1}$

$$
\int_{T_{0}}^{T_{\mathrm{R}}} \frac{\mathrm{d} T}{t_{0}(T)\left[1+\frac{a}{\beta} \exp \left(\frac{-\Delta H}{R T}\right)\right]}=r
$$

Van den Dool and Kratz's ${ }^{7}$ definition of the LTPRI is used in the final calculation.

\section{EXPERIMENTAL}

A Model 5790A gas chromatograph (Hewlett-Packard, Avondale, PA, U.S.A.) equipped with an HP 7672A auto-sampler was used for column testing. The instrument was provided with a two-point temperature calibration at 130.0 and $320.0^{\circ} \mathrm{C}$. The temperature control was better than $0.1^{\circ} \mathrm{C}$. An external high-precision pressure gauge was installed to allow pressure readings of 0.001 bar. An HP Model 3388 computer integrator was used for data handling.

A Mega Series 5300 gas chromatograph (Carlo Erba, Milan, Italy) was used for testing squalane columns. An external quartz thermometer (Type 2801, HewlettPackard) was used to correct the oven temperature under isothermal operation. A Spectra-Physics (Santa Clara, CA, U.S.A.) SP4290 integrator was used for data handling.

Four different cross-linked columns were randomly selected from the Ultra Performance series of Hewlett-Packard and two from Chrompack (Middelburg, The Netherlands). Their characteristics are given in Table I.

Helium was used as the carrier gas. The septum-flush flow-rate was $15 \mathrm{ml} / \mathrm{min}$; the splitting ratio was set at 1:100 for the HP 5790A and 1:200 for the Mega Series 5300 instruments. The temperatures of the injection port and detector block were set at $250^{\circ} \mathrm{C}$ for the HP $5790 \mathrm{~A}$ and $200^{\circ} \mathrm{C}$ for the Mega Series 5300 instruments.

Samples containing hydrocarbons, aromatics, ketones, esters and alcohols were used with both non-polar and weakly polar columns. AT-class microcomputers with math coprocessors were used for all computations. Software was written in Quick-Basic (Micro-Soft).

\section{TABLE I}

\section{COLUMN CHARACTERISTICS}

\begin{tabular}{llllll}
\hline $\begin{array}{l}\text { Column } \\
\text { No. }\end{array}$ & $\begin{array}{l}\text { Stationary } \\
\text { phase }\end{array}$ & $\begin{array}{l}\text { Length } \\
(\mathrm{m})\end{array}$ & $\begin{array}{l}\text { I.D. } \\
(\mathrm{mm})\end{array}$ & $\begin{array}{l}\text { Film thickness } \\
(\mu \mathrm{m})\end{array}$ & Manufacturer \\
\hline 1 & Squalane & 50 & 0.22 & 0.21 & Chrompack \\
2 & OV-1 & 25 & 0.31 & 0.52 & Hewlett-Packard \\
3 & SE-54 & 25 & 0.31 & 0.52 & Hewlett-Packard \\
4 & OV-1 & 20 & 0.32 & 1.2 & Chrompack \\
5 & OV-1 & 25 & 0.31 & 0.52 & Hewlett-Packard \\
6 & SE-54 & 25 & 0.31 & 0.52 & Hewlett-Packard
\end{tabular}




\section{RESULTS AND DISCUSSION}

The reliability of the calculated LTPRI is influenced by several factors, viz., $\Delta H / R T, \Delta S / R, \beta, t_{0}(T)$ and the accuracy of the isothermal data used for the calculation; for clarity, we discuss them separately.

\section{Temperature dependence of entropy and enthalpy terms}

As both the entropy and enthalpy terms ( $c f$., eqns. 5 and 6 ) are temperature dependent, their values determined according to the procedure used in refs. 1-3 and the approach proposed in this paper are actually average values between the two temperatures of the isothermal measurements. The values of both terms depend not only on the temperatures of the isothermal measurements, but also on the difference between the two temperatures. When the elution temperature of a component is much higher than the upper isothermal measurement temperature, the term $\alpha / \beta \exp [-\Delta H /(R T)]$ will be smaller than it should be ( $c f$. , data in ref. 1, Table 3$)$, and the calculated $T_{\mathrm{r}}$ will be lower than the experimental value. Therefore, the optimum temperatures for measuring the isothermal retention indices should be selected as discussed by Curvers et al. ${ }^{1}$, in order to obtain a better fit with the calculated and experimental LTPRIs.

The influence of the selected isothermal temperatures on the calculated LTPRI is different in both concepts. The retention temperatures of components and the adjacent $n$-alkanes are calculated using entropy and enthalpy terms obtained under identical conditions. In our approach, this is accomplished by using (a) the Kovats retention indices at two isothermal temperatures (which are known to have very good column-to-column reproducibility) and (b) the adjusted retention times of $n$-alkanes at two corresponding isothermal temperatures measured on the column to be used.

Systematic errors are partially cancelled in the calculation of LTPRI, because the shifts of the calculated $T_{\mathrm{r}}$ for a given component and the adjacent $n$-alkanes are in the same direction and of a similar magnitude. A comparison of calculated and measured LTPRIs is presented in Tables II-V for four columns differing either in stationary phase or film thickness, with different programming rates. The differences between the measured and calculated retention indices are within 0.5 retention index units (i.u.) in all instances, except for 1-butanol, for which there is a non-linear relationship between $\ln k$ and $1 / T$. Note that the elution temperatures of some components (in the bottom parts of Tables III and IV at a programming rate of $8^{\circ} \mathrm{C} / \mathrm{min}$ ) are much higher than the temperatures in the isothermal measurements, and these do not cause an additional crror in the calculated LTPRI. Unlike in the former approach ${ }^{1}$, the choice of temperature in isothermal measurements is not so critical with the procedure presented here. Considering both the analysis time and the accuracy of the measurement, a capacity ratio $\left(k^{\prime}\right)$ between 0.5 and 30 should be satisfactory. The temperature difference between the two measurements should be as large as possible.

\section{Effect of film thickness and phase ratio}

The entropy and enthalpy terms of some components on columns 2 and 4 are given in Table VI. The values were calculated using tabulated Kováts retention indices measured on column 2 at two temperatures and the adjusted retention times of $n$-alkanes obtained from two isothermal runs for each column. The agreement of the 
TABLE II

COMPARISON OF CALCULATED AND MEASURED LTPRI VALUES ON COLUMN 1 (SQUALANE)

$T_{0}=40.0^{\circ} \mathrm{C}$.

\begin{tabular}{|c|c|c|c|c|c|c|c|c|}
\hline \multirow[t]{3}{*}{ Component } & \multicolumn{2}{|c|}{ Isothermal $\left({ }^{\circ} \mathrm{C}\right)$} & \multicolumn{4}{|c|}{ Programming rate $\left({ }^{\circ} \mathrm{C} / \mathrm{min}\right)$} & & \\
\hline & \multirow[t]{2}{*}{50.0} & \multirow[t]{2}{*}{70.0} & \multicolumn{2}{|l|}{1.5} & \multicolumn{2}{|l|}{2.5} & & \\
\hline & & & $I_{\text {calc. }}{ }^{a}$ & $\Delta I^{a}$ & $I_{\text {calc. }}{ }^{a}$ & $\Delta I^{a}$ & & \\
\hline 2,2-Dimethylpentane & 625.6 & 626.9 & 617.8 & -0.1 & 618.6 & -0.1 & & \\
\hline 2,4-Dimethylpentane & 629.8 & 630.5 & 621.4 & 0.0 & 622.2 & 0.0 & & \\
\hline Benzene & 637.2 & 641.8 & 626.7 & -0.3 & 628.1 & -0.3 & & \\
\hline 3,3-Dimethylpentane & 658.9 & 661.5 & 648.0 & 0.0 & 649.5 & 0.1 & & \\
\hline 2-Methylhexane & 666.6 & 666.9 & 657.0 & -0.2 & 658.1 & -0.1 & & \\
\hline 1-cis, 3-Dimethylcyclopentane & 682.7 & 686.0 & 675.6 & 0.3 & 676.9 & 0.3 & & \\
\hline 3-Ethylpentane & 686.0 & 687.1 & 680.4 & 0.0 & 681.2 & -0.1 & & \\
\hline 2,5-Dimethylhexane & 728.4 & 729.0 & 722.5 & -0.1 & 723.7 & -0.1 & & \\
\hline 2,4-Dimethylhexane & 731.9 & 732.9 & 725.6 & -0.1 & 727.0 & 0.0 & & \\
\hline Ethylcyclopentane & 733.8 & 737.5 & 727.0 & 0.3 & 728.9 & 0.2 & & \\
\hline 2,3-Dimethylhexane & 760.1 & 761.5 & 753.1 & 0.2 & 754.9 & 0.3 & & \\
\hline 3,4-Dimethylhexane & 770.6 & 772.6 & 764.6 & 0.1 & 766.4 & 0.0 & & \\
\hline 1-cis, 3-Dimethylcyclohexane & 785.0 & 789.8 & 781.5 & 0.3 & 783.8 & 0.4 & & \\
\hline 1-trans, 2-Dimethylcyclohexane & 801.8 & 807.5 & 802.0 & 0.3 & 803.5 & 0.4 & & \\
\hline 1-trans, 3-Dimethylcyclohexane & 805.6 & 810.8 & 805.3 & 0.4 & 806.8 & 0.4 & & \\
\hline Ethylbenzene & 834.6 & 839.8 & 832.4 & 0.4 & 835.1 & 0.5 & & \\
\hline Isopropylcyclopentane & 812.1 & 817.0 & 811.1 & 0.3 & 812.9 & 0.4 & & \\
\hline 1,4-Dimethylbenzene & 849.1 & 854.0 & 847.0 & 0.3 & 849.9 & 0.5 & & \\
\hline \multirow[t]{3}{*}{ Component } & \multicolumn{2}{|c|}{ Isothermal $\left({ }^{\circ} \mathrm{C}\right)$} & \multicolumn{6}{|c|}{ Programming rate $\left({ }^{\circ} \mathrm{C} / \mathrm{min}\right)$} \\
\hline & \multirow[t]{2}{*}{50.0} & \multirow[t]{2}{*}{70.0} & \multicolumn{2}{|l|}{1.0} & \multicolumn{2}{|l|}{2.0} & \multicolumn{2}{|l|}{3.0} \\
\hline & & & $I_{\text {calc. }}^{a}$ & $\Delta I^{a}$ & $I_{\text {calc. }}{ }^{a}$ & $\Delta I^{a}$ & $I_{\text {calc. }}^{a}$ & $\Delta I^{a}$ \\
\hline 2-Methyl-2-butene & 514.3 & 514.4 & 508.9 & -0.1 & 509.1 & -0.1 & 509.2 & -0.2 \\
\hline 4-Methyl-1-pentene & 549.4 & 550.4 & 536.8 & 0.0 & 537.5 & 0.0 & 538.0 & -0.1 \\
\hline 2,3-Dimethylbutane & 567.3 & 568.8 & 555.2 & -0.1 & 556.0 & 0.0 & 556.6 & -0.1 \\
\hline 2-Methyl-1-pentene & 580.1 & 580.5 & 571.3 & -0.1 & 571.8 & -0.1 & 572.3 & -0.1 \\
\hline Methylcyclopentane & 627.9 & 630.9 & 618.7 & 0.2 & 619.9 & 0.3 & 620.8 & 0.3 \\
\hline 2,4-Dimethylpentane & 629.8 & 630.5 & 620.9 & -0.1 & 621.9 & -0.1 & 622.6 & -0.1 \\
\hline Benzene & 637.2 & 641.8 & 625.9 & -0.4 & 627.5 & -0.3 & 628.7 & -0.3 \\
\hline Cyclohexane & 662.7 & 667.1 & 650.6 & 0.3 & 652.6 & 0.4 & 654.2 & 0.5 \\
\hline 2-Methylhexane & 666.6 & 666.9 & 656.4 & -0.1 & 657.7 & -0.1 & 658.7 & 0.0 \\
\hline 1-Heptene & 681.8 & 682.3 & 674.6 & -0.2 & 675.7 & -0.1 & 676.4 & -0.1 \\
\hline
\end{tabular}

" In all tables, $\Delta I=$ LTPRI(calculated) - LTPRI(measured).

Kováts retention indices measured on both columns ( $c f$., Tables III and V) is within 0.3 i.u. for the test sample, although the columns have a different film thickness or phase ratio and are from different manufacturers.

The ratio $\beta$ (column 2) $/ \beta$ (column 4 ) was found to be 2.3 from the specification of 


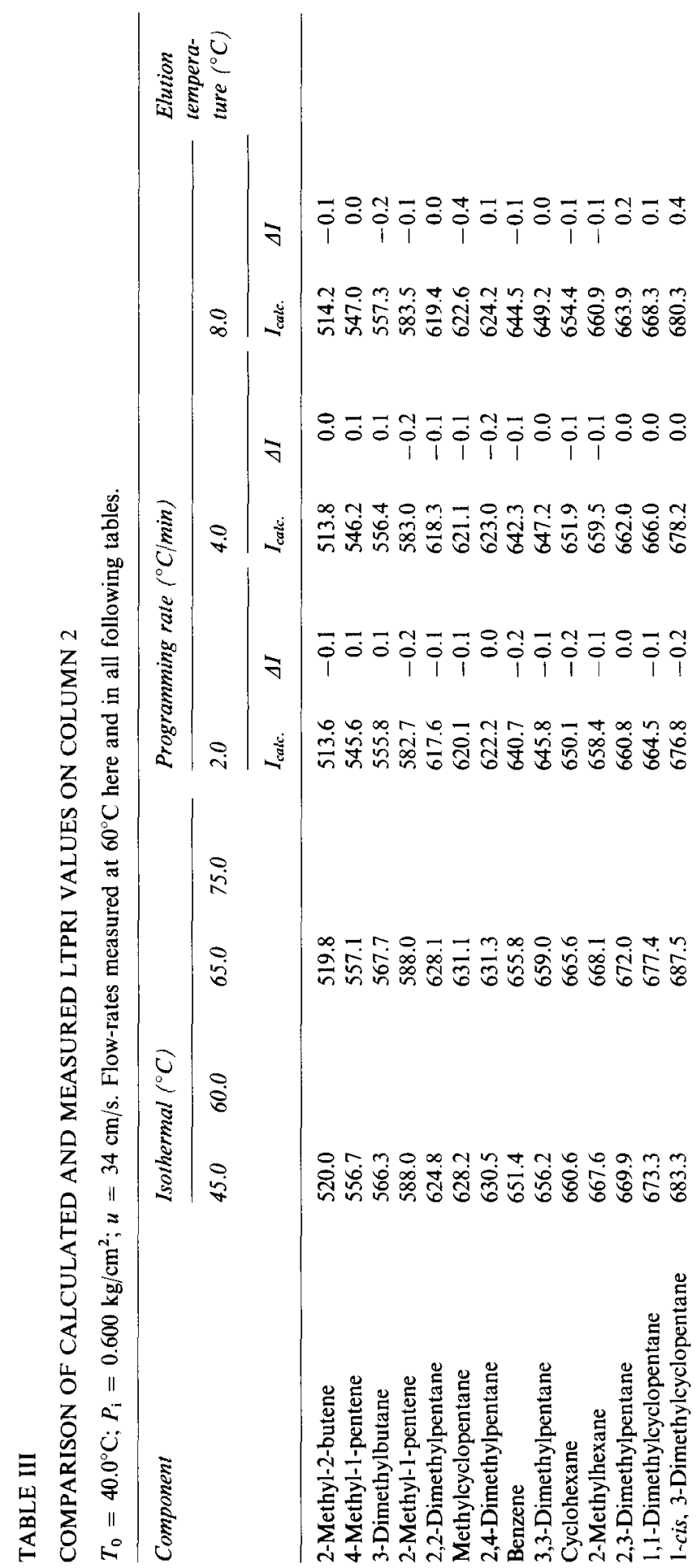




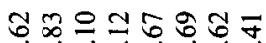

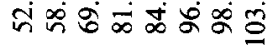

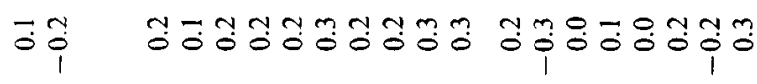

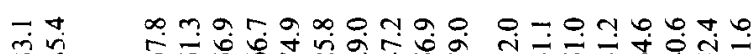

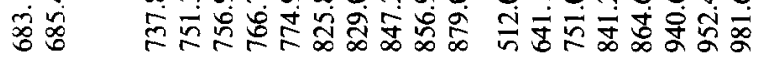

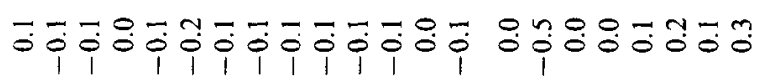

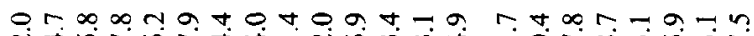

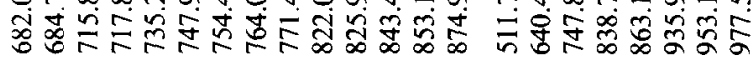

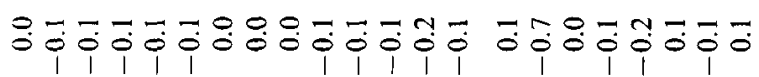

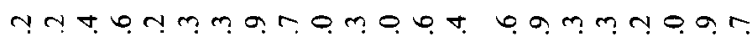

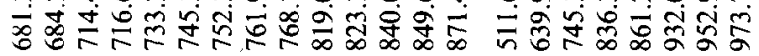

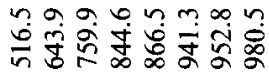

$n-\infty, 0+4-m \infty$ n

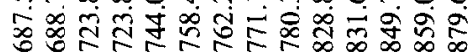

9. $\infty$ 의

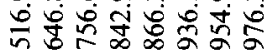

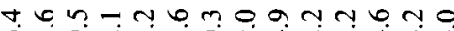

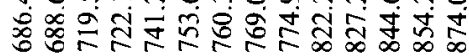

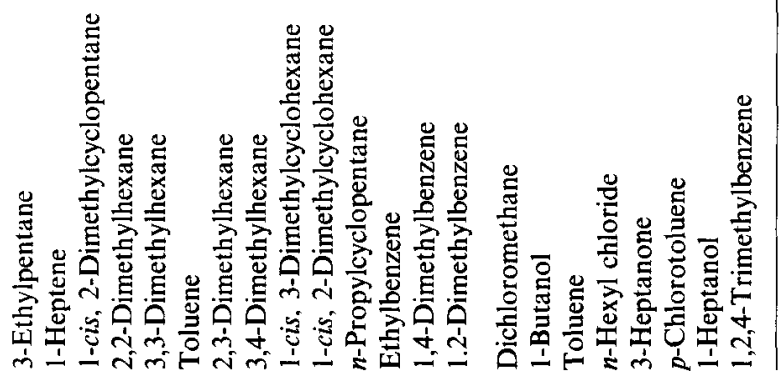




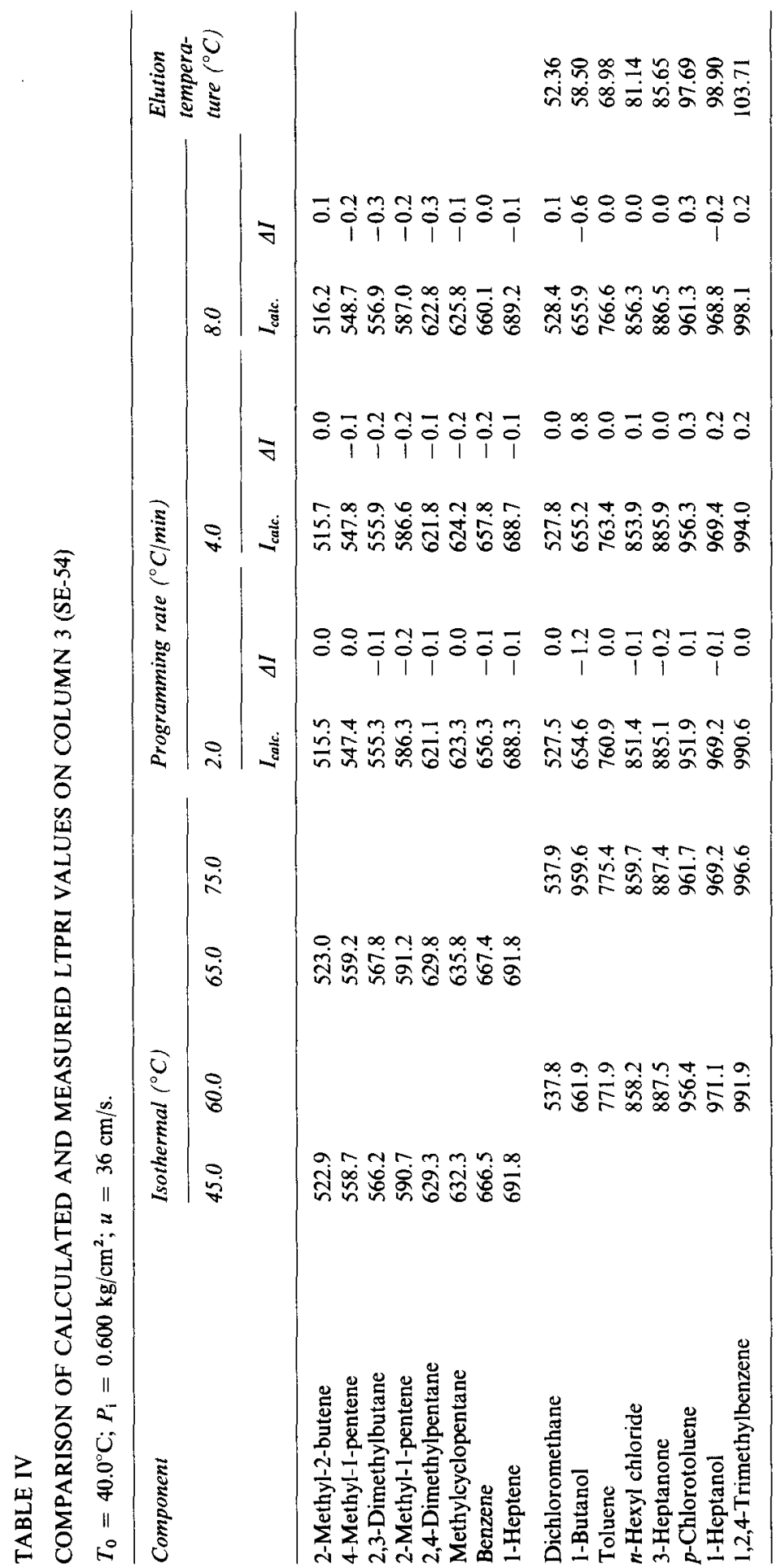


TABLE V

COMPARISON OF CALCULATED AND MEASURED LTPRI VALUES ON COLUMN 4

$T_{0}=40.0^{\circ} \mathrm{C}$.

\begin{tabular}{|c|c|c|c|c|c|c|c|c|}
\hline \multirow[t]{3}{*}{ Component } & \multicolumn{2}{|c|}{ Isothermal $\left({ }^{\circ} \mathrm{C}\right)$} & \multicolumn{6}{|c|}{ Programming rate $\left({ }^{\circ} \mathrm{C} / \mathrm{min}\right)$} \\
\hline & \multirow[t]{2}{*}{45.0} & \multirow[t]{2}{*}{65.0} & \multicolumn{2}{|l|}{2.0} & \multicolumn{2}{|l|}{4.0} & \multicolumn{2}{|l|}{8.0} \\
\hline & & & $I_{\text {calc. }}$ & $\Delta I$ & $I_{\text {caic. }}$ & $\Delta I$ & $I_{\text {calc. }}$ & $\Delta I$ \\
\hline 2-Methyl-2-butene & 520.0 & 519.8 & 513.7 & 0.0 & 514.1 & 0.1 & 514.7 & 0.1 \\
\hline 4-Methyl-1-pentene & 556.7 & 557.1 & 546.0 & 0.2 & 546.9 & 0.3 & 548.2 & 0.4 \\
\hline 2,3-Dimethylbutane & 566.3 & 567.7 & 556.2 & 0.2 & 557.1 & 0.2 & 558.6 & 0.3 \\
\hline 2-Methyl-1-pentene & 588.0 & 588.0 & 583.0 & 0.1 & 583.5 & -0.1 & 584.1 & 0.0 \\
\hline MethylCyclopentane & 628.2 & 631.3 & 620.9 & 0.1 & 622.3 & 0.1 & & \\
\hline 2,4-Dimethylpentane & 630.4 & 631.3 & 623.0 & 0.0 & 624.2 & 0.0 & & \\
\hline Benzene & 651.3 & 655.4 & 642.0 & 0.2 & 644.2 & 0.5 & 647.2 & 0.6 \\
\hline Cyclohexane & 660.6 & 665.6 & 651.6 & 0.2 & 654.0 & 0.4 & 657.3 & 0.6 \\
\hline 2-Methylhexane & 667.6 & 667.7 & 659.5 & 0.1 & 661.0 & 0.0 & 662.8 & 0.0 \\
\hline 1-Heptene & 688.6 & 688.7 & 684.7 & 0.0 & 685.5 & 0.0 & 686.4 & 0.0 \\
\hline
\end{tabular}

the columns. However, the ratio of the entropy terms of a component $[(\alpha / \beta)$ (column $4] /[(\alpha / \beta)$ (column 2)] between the two columns is larger than 4 (cf., Table VI). The deviation from theory could be the result of inaccurate values of the phase ratio or the strong surface effect on the stationary phase. The latter causes the properties of a coated stationary phase to deviate from that of the bulk system, and the entropy and enthalpy of a component to depend on the film thickness. In either instance, it is possible to correct this ratio based on the entropy terms of a known component measured on both columns, without the need to know the absolute values of the phase ratios or the degree of the surface effect. With this correction, the Curvers et al. concept ${ }^{1,2}$ is still valid if the enthalpy terms are constant.

TABLE VI

CALCULATED ENTROPY AND ENTHALPY TERMS ON COLUMNS 2 and 4

\begin{tabular}{|c|c|c|c|c|}
\hline \multirow[t]{2}{*}{ Component } & \multicolumn{2}{|c|}{$\alpha / \beta\left(\times 10^{-7}\right)$} & \multicolumn{2}{|c|}{$-\Delta H / R(K)$} \\
\hline & Column 2 & Column 4 & Column 2 & Column 4 \\
\hline 2-Methyl-2-butene & 398.25 & 1624.4 & 2890.7 & 2753.8 \\
\hline 4-Methyl-1-pentene & 339.86 & 1377.4 & 3048.1 & 2913.6 \\
\hline 2,3-Dimethylbutane & 367.54 & 1487.4 & 3051.1 & 2917.2 \\
\hline 2-Methyl-1-pentene & 264.38 & 1065.3 & 3219.1 & 3086.8 \\
\hline$n$-Hexane & 242.05 & 973.22 & 3282.3 & 3150.8 \\
\hline Methylcyclopentane & 303.87 & 1231.8 & 3290.8 & 3156.5 \\
\hline Benzene & 288.90 & 1179.1 & 3373.4 & 3236.8 \\
\hline Cyclohexane & 305.44 & 1250.0 & 3382.3 & 3244.8 \\
\hline 2-Methylhexane & 149.81 & 614.36 & 3629.1 & 3490.9 \\
\hline 2,4-Dimethylpentane & 219.03 & 888.52 & 3401.5 & 3267.0 \\
\hline 1-Heptene & 127.33 & 525.39 & 3741.1 & 3600.8 \\
\hline$n$-Heptane & 115.96 & 480.10 & 3803.6 & 3662.2 \\
\hline
\end{tabular}


The data in Table VI showed that the enthalpy terms on the two columns were not consistent. Their differences are about $4 \%$ on average, which alone could generate at least a $30 \mathrm{i} . \mathrm{u}$. difference in calculated LTPRIs if the enthalpy terms are taken as the basic data. The film thickness dependence of the enthalpy term invalidates the attempt to transfer the entropy and enthalpy terms from one column to another as proposed by Curvers et al. ${ }^{1}$.

The procedure described here corrects the variations in film thickness, phase ratio or the surface effect of the phase through measurements on $n$-alkanes under isothermal conditions, without the need to know them. The retention times of $n$-alkanes together with the Kováts retention indices are used to calculate the entropy and enthalpy terms of each component on the column to be used for analysis. It is as if all the components were measured on this column with this procedure, when the reproducibility of Kováts retention indices of different columns can be guaranteed. Note that some components, which have larger $\mathrm{d} I / \mathrm{d} T$ values (e.g., benzene and cyclohexane; $c f$., Table V) show slightly larger deviations between the calculated and mean real LTPRIs at higher programming rates for column 4 . The probable reason is that the average programming rate is smaller than expected, owing to bundling of the column coils. For all other columns the coils were regularly distributed in single layers on a light metal frame. The coils at the inner side of the bundle cannot follow the set programming rate. Obviously this deviation of the actual column temperature from the set value will have a larger effect on components with a high $\mathrm{d} I / \mathrm{d} T$.

\section{Effect of variation of Kováts retention indices}

As isothermal retention indices are used as the basic data for the calculation of LTPRIs, their variation between different columns will certainly have an influence on the LTPRIs. We studied this effect by varying the Kováts retention indices by \pm 0.5 i.u., which is an acceptable simulation of the real situation. The results in Table VII show that the error of calculated LTPRIs and the deviation of the Kováts retention indices used for the calculation are of the same order of magnitude or even less.

\section{Effect of variation of column dead time}

The column dead time reflects the integrated effects of column length and flow-rate. It has to be taken into account in the calculation of the elution temperature, $T_{\mathrm{r}}$, in temperature-programmed gas chromatography (cf., eqn. 7).

The column dead time, $t_{0}$, is cancelled in the calculation of LTPRI when measured data are used. In the calculation of $T_{\mathrm{r}}$, however, such a process is simulated, and the dead time $t_{0}(T)$ will certainly affect the $T_{\mathrm{r}}$ value. As the same dead time $t_{0}(T)$ is used for the calculation of the elution temperature of the components for a given programmed run, systematic errors in $t_{0}(T)$ can also be partly cancelled in the calculation of LTPRIs. From this point of view, some variation of $t_{0}(T)$ is acceptablc. The $t_{0}$ values under isothermal conditions are involved in the calculation of the adjusted retention times or capacity ratios of $n$-alkanes, and have a direct influence on the values of the entropy and enthalpy terms.

In this study, methane was used as the dead-time marker, not because it can give the best accuracy in $t_{0}$ measurements, but because most of the published data were measured using the retention lime of methane as $t_{0}$. The consistency in choosing the marker will improve the accuracy of the calculated LTPRIs, particularly for earlier 
TABLE VII

EFFECT OF VARIATION OF ISOTHERMAL RETENTION INDEX ON LTPRI

Calculated for Column 2. $T_{0}=40.0^{\circ} \mathrm{C} ; r=8.0^{\circ} \mathrm{C} / \mathrm{min}$.

\begin{tabular}{|c|c|c|c|}
\hline \multirow[t]{2}{*}{ Compound } & \multicolumn{2}{|c|}{ Isothermal ("C) } & \multirow[t]{2}{*}{$I_{\text {calc. }}$} \\
\hline & 60.0 & 75.0 & \\
\hline $\begin{array}{l}\text { Dichloromethane } \\
\text { Variation }\end{array}$ & $\begin{array}{l}516.90 \\
-0.50 \\
-0.50 \\
+0.0 \\
+0.0 \\
+0.50 \\
+0.50\end{array}$ & $\begin{array}{l}516.50 \\
+0.50 \\
+0.0 \\
+0.50 \\
-0.50 \\
+0.0 \\
+0.50\end{array}$ & $\begin{array}{r}512.0 \\
-1.0 \\
+0.3 \\
-0.3 \\
+0.3 \\
+0.7 \\
+0.4\end{array}$ \\
\hline $\begin{array}{l}\text { Toluene } \\
\text { Variation }\end{array}$ & $\begin{array}{l}756.62 \\
-0.50 \\
-0.50 \\
+0.0 \\
+0.0 \\
+0.50 \\
+0.50 \\
+0.50\end{array}$ & $\begin{array}{l}759.90 \\
+0.50 \\
+0.0 \\
-0.50 \\
+0.50 \\
+0.0 \\
-0.50 \\
+0.50\end{array}$ & $\begin{array}{r}751.0 \\
-0.9 \\
-0.7 \\
+0.1 \\
+0.2 \\
+0.6 \\
+0.9 \\
+0.5\end{array}$ \\
\hline $\begin{array}{l}p \text {-Chiorotoluene } \\
\text { Variation }\end{array}$ & $\begin{array}{l}936.25 \\
-0.50 \\
-0.50 \\
+0.0 \\
+0.0 \\
+0.50 \\
+0.50\end{array}$ & $\begin{array}{l}941.30 \\
+0.50 \\
+0.0 \\
+0.50 \\
-0.5 \\
+0.0 \\
-0.50\end{array}$ & $\begin{array}{r}940.6 \\
+0.4 \\
-0.1 \\
+0.5 \\
-0.5 \\
+0.1 \\
-0.4\end{array}$ \\
\hline
\end{tabular}

eluting components. This is illustrated in Table VIII, where LTPRIs were calculated using measured and extrapolated dead times on two different columns. For components having a retention index above 600 no significant differences were observed for the two methods.

\section{Influence of carrier flow-rate or inlet pressure}

For well deactivated columns and a sample amount far below the maximum capacity of the column, the entropy and enthalpy terms are expected to be independent of carrier gas flow-rate or inlet pressure under normal operating conditions, particularly when helium is used as the carrier gas and the inlet pressure is lower than 2 bar. For unknown reasons, the entropy and enthalpy terms are also affected by the flow-rate or pressure drop, as shown in Table IX. The data were calculated using measured Kováts retention indices and adjusted retention times of $n$-alkanes at corresponding isothermal temperatures at different inlet pressures. The effects of about a $1.5 \%$ variation in the entropy and enthalpy terms on the calculated LTPRI is shown in Table X. By comparison of these values with the results in Table IX, the error in the calculated LTPRIs caused only by the different flow-rate or inlet pressure can be calculated when the entropy and enthalpy terms are used as the basic data. 


\begin{tabular}{|c|c|c|c|c|c|c|c|c|}
\hline \multicolumn{9}{|c|}{$\begin{array}{l}\text { COMPARISON OF CALCULATED }{ }^{8} \text { AND MEASURED LTPRI VALUES ON COLUMNS } 2 \text { AND } 3 \text { USING } \\
\text { DIFFERENT } t_{0} \text { VALUES IN THE CALCULATION }\end{array}$} \\
\hline \multicolumn{9}{|c|}{$T_{0}=40.0^{\circ} \mathrm{C} ; r=8.0^{\circ} \mathrm{C} / \mathrm{min}$} \\
\hline \multirow[t]{3}{*}{ Component } & \multicolumn{4}{|l|}{ Column 2} & \multicolumn{4}{|l|}{ Column 3} \\
\hline & \multicolumn{4}{|l|}{ Calc. with } & \multicolumn{4}{|l|}{ Calc. with } \\
\hline & Measured $t_{0}$ & $\Delta I$ & Calc. $t_{0}$ & $\Delta I$ & Measured $t_{0}$ & $\Delta I$ & Calc. $t_{0}$ & $\Delta I$ \\
\hline Dichloromethane & 512.0 & 0.2 & 512.8 & 1.0 & 528.4 & 0.1 & 529.5 & 1.2 \\
\hline 4-Methyl-1-pentene & 547.0 & 0.0 & 548.0 & 1.0 & 548.7 & -0.2 & 549.7 & 0.8 \\
\hline Methylcyclopentane & 622.6 & -0.4 & 622.9 & -0.1 & 625.8 & -0.3 & 626.2 & 0.1 \\
\hline 1-Heptene & 685.4 & -0.2 & 685.6 & 0.0 & 689.2 & -0.1 & 689.4 & 0.1 \\
\hline Toluene & 751.0 & 0.0 & 751.2 & 0.2 & 766.6 & 0.0 & 766.8 & 0.2 \\
\hline n-Hexyl chloride & 841.2 & 0.1 & 841.3 & 0.2 & 856.3 & 0.0 & 856.4 & 0.1 \\
\hline 3-Heptanone & 64.6 & 0.0 & 864.7 & 0.1 & 886.6 & 0.1 & 886.6 & 0.1 \\
\hline$p$-Chlorotoluene & 940.6 & 0.2 & 940.7 & 0.3 & 961.3 & 0.3 & 961.4 & 0.4 \\
\hline 1-Heptanol & 952.4 & -0.2 & 952.4 & -0.2 & 968.8 & -0.2 & 968.8 & -0.2 \\
\hline 1,2,4-Trimethylbenzene & 981.6 & 0.3 & 981.7 & 0.4 & 998.1 & 0.2 & 998.1 & 0.2 \\
\hline
\end{tabular}

These effects are avoided when using the procedure proposed in this paper. The results for both measured and calculated LTPRIs for two different columns at two different flow-rates or inlet pressures are given in Table XI and also Tables III and IV. The error was less than 0.4 i.u. for all the components tested, except the first

\section{TABLE IX}

VARIATION OF ENTROPY AND ENTHALPY TERMS WITH CARRIER FLOW-RATE OR INLET PRESSURE

Measured on column 2. $-\Delta H / R$ in Kelvin.

\begin{tabular}{|c|c|c|c|c|c|c|c|c|}
\hline \multirow[t]{3}{*}{ Component } & \multicolumn{8}{|c|}{ Inlet pressure $\left(\mathrm{kg} / \mathrm{cm}^{2}\right)$} \\
\hline & \multicolumn{2}{|l|}{0.300} & \multicolumn{2}{|l|}{0.450} & \multicolumn{2}{|l|}{0.600} & \multicolumn{2}{|l|}{0.800} \\
\hline & $-\Delta H / R$ & $\alpha / \beta^{a}$ & $-\Delta H / R$ & $\alpha / \beta^{a}$ & $-\Delta H / R$ & $\alpha / \beta^{a}$ & $-\Delta H / R$ & $\alpha / \beta^{a}$ \\
\hline 2-Methyl-2-butene & 2884.1 & 400.80 & 2867.3 & 424.96 & 2890.7 & 398.25 & 2923.6 & 353.52 \\
\hline 4-Methyl-1-pentene & 3041.9 & 341.88 & 3037.1 & 348.98 & 3048.1 & 339.86 & 3055.0 & 327.73 \\
\hline 2,3-Dimethylbutane & 3047.8 & 366.94 & 3049.3 & 366.98 & 3051.1 & 367.54 & 3069.3 & 342.25 \\
\hline 2-Methyl-1-pentene & 3212.9 & 266.55 & 3217.8 & 264.11 & 3219.1 & 264.38 & 3225.3 & 255.71 \\
\hline$n$-Hexane & 3278.9 & 241.89 & 3283.4 & 239.85 & 3282.3 & 242.05 & 3289.8 & 233.26 \\
\hline Methylcyclopentane & 3292.4 & 299.24 & 3294.6 & 298.68 & 3290.8 & 303.87 & 3299.1 & 292.28 \\
\hline 2,4-Dimethylpentane & 3400.1 & 217.56 & 3402.5 & 217.14 & 3401.5 & 219.03 & 3408.9 & 211.29 \\
\hline Benzene & 3361.7 & 296.43 & 3363.3 & 296.48 & 3373.4 & 288.90 & 3371.0 & 287.23 \\
\hline Cyclohexane & 3371.6 & 312.46 & 3376.4 & 309.32 & 3382.3 & 305.44 & 3382.7 & 301.13 \\
\hline 2-Methylhexane & 3630.5 & 147.48 & 3624.3 & 151.21 & 3629.1 & 149.81 & 3631.7 & 146.66 \\
\hline 1-Heptene & 3723.9 & 132.98 & 3729.3 & 131.40 & 3741.1 & 127.33 & 3740.4 & 125.98 \\
\hline$n$-Heptane & 3788.0 & 120.41 & 3791.6 & 119.74 & 3803.6 & 115.96 & 3798.5 & 116.25 \\
\hline
\end{tabular}




\section{TABLE X}

EFFECT OF VARIATION OF ENTROPY AND ENTHALPY TERMS ON THE LTPRI VALUES $T_{0}=40.0^{\circ} \mathrm{C} ; r=8.0^{\circ} \mathrm{C} / \mathrm{min}$. Measured on column 2 .

\begin{tabular}{lllll}
\hline \multicolumn{2}{l}{ Isothermal $\left({ }^{\circ} \mathrm{C}\right)$} & $\begin{array}{l}-\Delta H / R \\
(K)\end{array}$ & $\alpha / \beta\left(\times 10^{-7}\right)$ & $I_{\text {calc. }}$ \\
\cline { 1 - 3 } 60.0 & 75.0 & & & \\
\hline 756.62 & 759.90 & 3788.2 & 191.99 & 750.9 \\
757.52 & 700.90 & 3787.0 & 194.11 & 751.9 \\
800.00 & 800.00 & 4200.9 & 79.33 & 800.0 \\
842.88 & 844.63 & 4321.9 & 78.13 & 840.5 \\
954.92 & 952.77 & 5123.3 & 17.45 & 952.4 \\
955.60 & 953.50 & 5123.9 & 17.51 & 953.1 \\
\hline
\end{tabular}

component, 1-butanol. The reason for this close fit is that the entropy and enthalpy terms of each component were calculated based on the adjusted retention times of $n$-alkanes measured at the same inlet pressure condition to be used for the temperature-programmed run, and tabulated Kováts retention indices. This approach ensures the accuracy of the calculated LTPRI's, which is demonstrated further in Table XII for two different columns at different flow-rates for different structural types of substances.

\section{CONCLUSION}

For a given stationary phase and a given component at a given temperature, the entropy and enthalpy terms vary according to the film thickness or phase ratio, and

TABLE XI

COMPARISON OF CALCULATED AND MEASURED LTPRI VALUES ON COLUMNS 2 AND 3 AT $P_{\mathrm{i}}=0.450 \mathrm{~kg} / \mathrm{cm}^{2}$

$T_{0}=40^{\circ} \mathrm{C} ; r=8.0^{\circ} \mathrm{C} / \mathrm{min}$. Flow-rate $26 \mathrm{~cm} / \mathrm{s}$.

\begin{tabular}{|c|c|c|c|c|}
\hline \multirow[t]{2}{*}{ Component } & \multicolumn{2}{|c|}{ Column 2} & \multicolumn{2}{|c|}{ Column 3} \\
\hline & $I_{c a l c}$ & $\Delta I$ & $I_{\text {calc. }}$ & $\Delta I$ \\
\hline 2-Methyl-2-butene & 514.3 & 0.0 & 516.3 & -0.1 \\
\hline 4-Methyl-1-pentene & 547.3 & -0.1 & 549.1 & -0.1 \\
\hline 2,3-Dimethylbutane & 557.8 & -0.2 & 557.5 & 0.1 \\
\hline 2-Methyl-1-pentene & 583.8 & 0.0 & 587.3 & 0.0 \\
\hline Methylcyclopentane & \multirow{2}{*}{\multicolumn{2}{|c|}{ Co-elute }} & 626.6 & -0.1 \\
\hline 2,4-Dimethylpentane & & & 623.3 & -0.1 \\
\hline Benzene & 645.6 & -0.1 & 661.3 & 0.3 \\
\hline Cyclohexane & 655.5 & -0.1 & \multicolumn{2}{|c|}{ Co-elutes with benzene } \\
\hline 2-Methylhexane & 661.3 & -0.2 & \multicolumn{2}{|c|}{ Co-elutes with benzene } \\
\hline 1-Heptene & 685.7 & -0.1 & 689.5 & 0.0 \\
\hline
\end{tabular}




\section{TABLE XII}

COMPARISON OF CALCULATED AND MEASURED LTPRI VALUES ON COLUMNS 5 AND 6 AT DIFFERENT FLOW-RATES

$T_{0}=35.0^{\circ} \mathrm{C} ; r=8.0^{\circ} \mathrm{C} / \mathrm{min}$.

\begin{tabular}{|c|c|c|c|c|c|c|c|c|c|c|c|c|}
\hline \multirow[t]{4}{*}{ Component } & \multicolumn{6}{|c|}{ Column 5} & \multicolumn{6}{|c|}{ Column 6} \\
\hline & \multicolumn{2}{|c|}{ Isothermal $\left({ }^{\circ} \mathrm{C}\right)$} & \multicolumn{4}{|c|}{$L T P R I$ at flow-rate $(\mathrm{cm} / \mathrm{s})$} & \multicolumn{2}{|c|}{ Isothermal $\left({ }^{\circ} \mathrm{C}\right)$} & \multicolumn{3}{|c|}{ LTPRI at flow-rate $(\mathrm{cm} / \mathrm{s})$} & \\
\hline & \multirow[t]{2}{*}{60.0} & \multirow[t]{2}{*}{80.0} & \multicolumn{2}{|l|}{38} & \multicolumn{2}{|l|}{26} & \multirow[t]{2}{*}{60.0} & \multirow[t]{2}{*}{80.0} & \multicolumn{2}{|l|}{38} & \multicolumn{2}{|l|}{26} \\
\hline & & & $I_{\text {calc. }}$ & $\Delta I$ & $l_{\text {calc. }}$ & $\Delta I$ & & & $I_{\text {calc. }}$ & $\Delta I$ & $I_{\text {calc. }}$ & $\Delta I$ \\
\hline Benzene & 654.37 & 658.77 & 643.30 & -0.2 & 645.07 & -0.1 & 669.71 & 673.97 & 659.28 & 0.2 & 661.00 & 0.4 \\
\hline Isobutyl acetate & 757.79 & 755.73 & 754.24 & -0.5 & 754.82 & -0.4 & 774.16 & 771.94 & 771.51 & -0.1 & 771.80 & -0.1 \\
\hline 2-Methoxyethyl acetate & 810.99 & 807.11 & 811.04 & -0.4 & 810.33 & -0.4 & 838.31 & 834.21 & 836.94 & 0.0 & 836.48 & 0.0 \\
\hline Cyclohexanone & 860.93 & 867.57 & 859.15 & -0.4 & 862,12 & -0.3 & 894.47 & 900.00 & 895.34 & 0.1 & 897.22 & -0.3 \\
\hline 2-Ethoxyethyl acetate & 882.41 & 878.15 & 880.94 & -0.2 & 879.90 & -0.3 & 909.22 & 904.54 & 908.02 & 0.1 & 906.51 & 0.0 \\
\hline 2-(2-Methoxyethoxy)ethanol & 906.07 & 906.00 & 905.97 & -0.5 & 906.04 & -0.8 & 934.85 & 934.77 & 934.56 & -0.1 & 934.88 & -0.2 \\
\hline 2-(2-Ethoxyethoxy)ethanol & 974.79 & 974.44 & 974.47 & -0.2 & 974.62 & -0.4 & & & & & & \\
\hline
\end{tabular}


even the carrier gas flow-rate or inlet pressure. The procedure proposed here utilizes the Kováts retention index, which represents the common properties of a given stationary phase for each component, and the adjusted retention time or capacity ratio of $n$-alkanes, which represents the characteristics of each column. When the reproducibility of the Kováts retention index can be guaranteed, combining these two features (using eqns. 5 and 6 ) is equivalent to measuring all the components on the particular column. This is why the calculated LTPRI fits the experimental results so well. This procedure can easily be used for interactive database compound identification in linear temperature programmed capillary gas chromatography.

\section{REFERENCES}

1 J. Curvers, J. Rijks and C. Cramers, J. High Resolut. Chromatogr. Chromatogr. Commun., 8 (1985) 607.

2 J. Curvers, Thesis, Eindhoven University of Technology, Eindhoven, 1985.

3 E. E. Akporhonor, S. Le Vent and D. R. Taylor, J. Chromatogr., 405 (1987) 67.

4 J. Krupčik, P. Cellar, D. Repka, J. Garaj and G. Guiochon, J. Chromatogr., 351 (1986) 111

5 R. V. Golovnya and V. P. Uraletz, J. Chromatogr., 36 (1968) 276.

6 L. Erdey, J. Takács and E. Szaláncy, J. C'hromatogr., 46 (1970) 29.

7 H. van den Dool and P. D. Kratz, J. Chromatogr., 11 (1963) 463.

8 M. L. Peterson and J. Hirsch, J. Lipid Res., 1 (1959) 132. 